\title{
ESP LEARNER MOTIVATIONS AND PERCEPTIONS TOWARDS INTERNATIONAL ONLINE LETTER EXCHANGE PROGRAM
}

\author{
${ }^{1}$ Hafida Ruminar, ${ }^{2}$ Putri Gayatri, ${ }^{3}$ Dian Islami Prasetyaningrum \\ Universitas Brawijaya Malang \\ hafidaruminar@ub.ac.id
}

\begin{abstract}
The Online Letter Exchange Program (OLEP) was an online collaborative learning program hosted by the Faculty of Agriculture of the University of Miyazaki, Japan. It has collaborated with the Faculty of Agriculture in one of the private universities in Malang. The program is designed to encourage students' written communication skills and facilitate students with intensive real-life English communication experience with other students around Asia. The participant countries are from Japan, Taiwan, China, and Indonesia. One of its uniqueness lies in the policy that the participants share their specific fields, including agriculture and related fields. This study sought to investigate the intrinsic and extrinsic motivation and perception of the students towards the OLEP as it was supplementary activity. The perception included the topic, the platform, and interaction. The data were gained from questionnaires and interviews and were then analyzed using thematic analysis. The result showed that extrinsic motivation was dominant in completing the task in OLEP. The positive and negative perception of the three aspects would be a valuable source for those who attempt a similar online letter exchange program.
\end{abstract}

Keywords: motivation, perception, online letter exchange program

\section{INTRODUCTION}

As the Indonesian government regulates that English should be lectured to all students in all study programs (Indrasari, 2016), the ESP course has been commonly implemented to non-English department students in Indonesian universities (Agustina, 2014). The concept of ESP has been initiated in the 1960s, starting its debut in the technical texts-analysis terrain and flourishing well from time to time to satisfy professional or vocational language (Johns, 2012). Furthermore, it is well known as the English teaching practice to a diverse range of science (Nurakhir \& Palupi, 2018). Therefore, ESP focuses more on language in context than on telling the students about language structures and grammar (Abu-Melhim, 2013).

In this global market competition, the ESP course sounds prominent because it provides the students with English skills in their field. However, teaching English in context is challenging. Since the English language is learned as a foreign language in Indonesia, the students have no immediate need to communicate by using this language in their daily life. Therefore, a new program for ESP course, namely Online Letter Exchange Program (OLEP), is then developed at the Faculty of Agriculture in the chosen university in Malang, East Java, Indonesia, to enrich the students' experience in using the language. This program requires the students to communicate by using English to other Agriculture students from different 
countries. In other words, they are assigned to discuss any agricultural topic in English with their foreign friends.

ESP at the Faculty of Agriculture in the chosen university has three credits. However, since the program is new, it is included neither in the lecture nor the practicum seasons. It is an additional program where the students may get a little bonus score once they complete the program. As the students can disregard this new online program, it is valuable to probe their motivations and perceptions in accomplishing the OLEP. The result can be used to contemplate the program to provide better ESP experiences for the students.

Motivation is one of the essential determinants in the students' academic life (Buzdar, Mohsin, Akbar, \& Mohammad, 2017). It has been recognized that frequently, great eagerness and attitude are performed by highly motivated students. In contrast, students with low motivation tend to present a negative attitude in learning and achieving the goal (Wallace \& Leng Leong, 2020). The same belief also arises in English language learning practices. Vatankhah and Tanbakooei (2014) believe that motivation persists to function as an essential feature in English learning. In the same vein, Pavel (2020) admits that in ESP, such as English for Medical Purposes, motivation is considered the crucial facet required during the learning process.

Ryan and Deci (2000) describe motivation as enthusiasm to do something; someone who is excited to accomplish a particular thing is classified as motivated and vice versa. Furthermore, Ryan and Deci ( 2000) also argue that someone's motivation can differ not only in terms of level but also in orientation. Following up this idea, they introduce the notion of intrinsic and extrinsic motivation. Intrinsic motivation deals with the enthusiasm to do something because people enjoy it, are interested in it, or get satisfaction by doing it. On the other hand, extrinsic motivation is articulated as the willingness to do something because of the other consequences. For instance, a student's agreement to study at the university level is not because he enjoys studying; instead, it is because once he accomplished that program, his parents will be proud of him. Moreover, anchored in Ryan and Deci (2000), extrinsic motivation can be classified into four categories, which are external regulation, introjected regulation, Identification, and integration. They are described in this following figure: 
INTRINSIC AND EXTRINSIC MOTIVATIONS

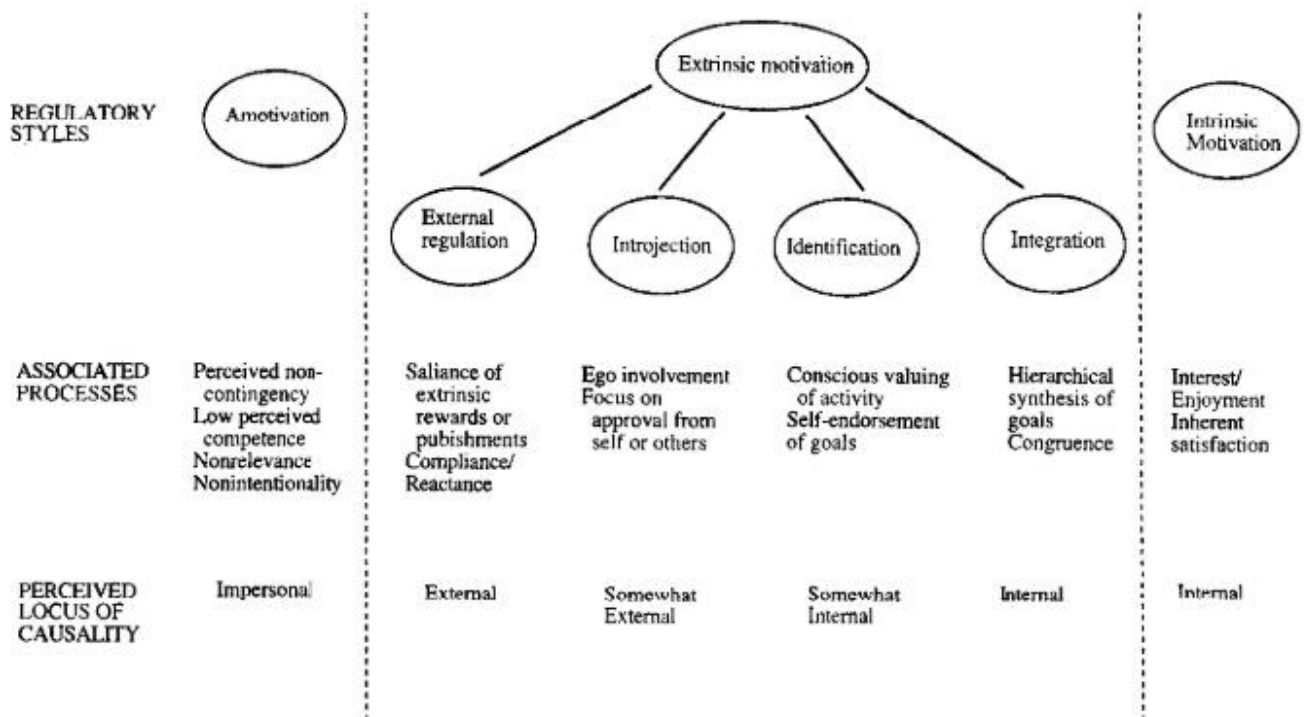

Figure 1. A taxonomy of human motivation by Ryan and Deci (2000, p. 61)

As seen in the above figure, Ryan and Deci (2000) depict external regulation as a condition whenever the action is conducted to gain an extrinsic reward or avoid a particular consequence. This type of extrinsic motivation is very contradictory to intrinsic motivation. On the other hand, the introjection is similar to external regulation that action is demonstrated to avoid guilt or obtain dignity. However, there is an involvement of self-esteem, such as ego involvement. The next classification of extrinsic motivation is Identification; it occurs once a person is not purely interested in doing the action or does not enjoy the action but can identify the importance of the action for him/herself. For instance, a student does not like to memorize the English vocabulary. Still, he understands that he has to memorize it to speak in English, which will furthermore improve his quality of life. Finally, the last category is integrated; it appears when there is full self-control in doing the action. However, unlike intrinsic motivation, although there is self-willingness, there is also an intention to get a separable outcome.

After all, even though, Buzdar et al. (2017, p. 80) found that academic performance correlates strongly and substantially with intrinsic and extrinsic motivation, Lemos and Veríssimo (2014) believe that intrinsic and extrinsic motivations contribute to different relationship toward the students' academic achievement. Therefore, it is essential to scrutinize the students' motivation, both intrinsically and extrinsically, and investigate their perception toward OLEP.

\section{METHOD}

\section{Respondents}

This study recruited thirty-five first-year students of an English for Agriculture class from the Agribusiness program at the Faculty of Agriculture in the chosen university. That class was chosen because only one class joined the 
OLEP, and one of the researchers taught that class at that time. The respondents consisted of seventeen males and eighteen females. Meanwhile, the students' corresponding mates were twenty-five Japanese, six Chinese, and four Taiwanese. All of the overseas students were from the Agriculture Department of the respective university.

\section{Instruments}

\section{Online questionnaire survey}

An online questionnaire consisting of fifteen items was used to obtain the data about students' perception and motivation towards OLEP (see appendix). There are ten multiple-choice questions about using an online platform and the topic provided and five open-ended questions regarding students' motivation and suggestions about the program. The questions were written in English, and the students also answer the questionnaire in English, although there were some answers mixed with Bahasa Indonesia.

\section{Progressive bar}

This program was a supplementary activity apart from the English lecture and practicum. Therefore, this research also identified the student's progressive bar to know their activeness during the program. The progressive bar color was blue at first, and it would turn into green if the students had finished the stage. The bar color would be red if they missed the stage or had not done all the stages. The requirement to complete each stage is by writing one post, followed by three replies to different international students. The students had two weeks to complete each stage. Based on the progressive bar, the researcher determined the interviewee who completed 50\% (1 person), 75\% (4 people), and 100\% (29 people) of the program. In the middle of the program, a student moved to another campus, so that she only completed $25 \%$ of the program (i.e., stage one) and excluded from this study. Nevertheless, the researcher only took five representatives from the students who completed $100 \%$ as the interviewee since only five respondents were agreed to be interviewed.

\section{Interview guide}

A semi-structured interview was employed to obtain more in-depth information from the students. The interview was conducted in Bahasa Indonesia to make the students comfortable in expressing their opinions. There were five main questions, followed by further questions based on the respondent's answer. The interview questions were related to students' obstacles in completing the stages, topics in OLEP, their motivation to complete the program, their opinion about the program and its platform, and their suggestions to improve the program. Ten interviewees were chosen based on their progress bar percentage in completing OLEP, as mentioned above.

\section{Procedures}

The program started from October to December 2019. It was an independent activity beyond the lecture and practicum, and it ran asynchronously utilizing the 
Moodle platform. The interface was similar to a blog and had a feature named students overview in a progress bar. It represented the stage that the student had completed. It had four stages with provided topics.

The hosting paired each Indonesian student with one of Japanese, Taiwan, or Chinese students, which later called buddy. In this research, the term online letter exchange represents the initial posting in each stage made by students, and the student's buddy had to reply to his/her pal's post. The students would be given a $10 \%$ additional score if they had completed all the stages to motivate the students to post regularly in OLEP. The scheme of the program was presented in Figure 2 as follows.

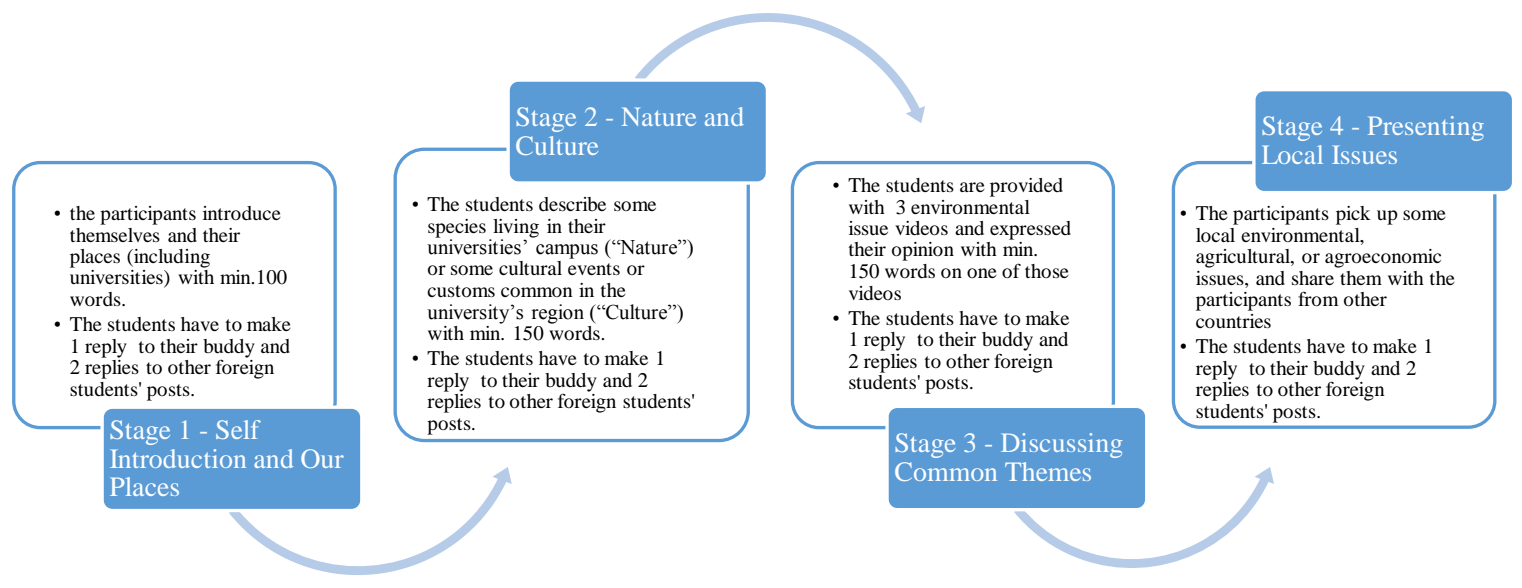

Figure 2. The process of Online Letter Exchange Program

\section{Data Collection}

The questionnaires for students were distributed at the end of the program in December using Google form. Following the data collection procedure, the researchers purposely interview a student who completed $50 \%$, four students who completed $75 \%$, and five random representative students who completed $100 \%$ of the program. The interview lasted around fifteen to twenty minutes for each student. All the interviewees were interviewed at the scheduled time and recorded using a mobile phone.

\section{Data analysis}

The interview results were transcribed, and the questionnaire responses were collated automatically by Google form. Furthermore, all the data were analyzed using thematic analysis. While identifying the data, two themes were discovered, namely perception and motivation. The questionnaire and interview results were then classified and coded based on both themes and removed the unnecessary data that was not related to the topics, such as students' cultural views on this program. This research results portrayed the students' perception, which included the 
platform, topics in OLEP, and interactions, and the theme motivation covered intrinsic and extrinsic factors that motivate students to join the program and complete the tasks.

\section{FINDINGS AND DISCUSSIONS}

\section{Student's Motivation}

The results of this research portrayed two types of motivations that drove students in completing the task in OLEP, namely intrinsic and extrinsic motivation that would be discussed further in this section. The survey results showed that more than $80 \%$ of the students enjoyed OLEP, and almost half of it stated that they enjoy this program a lot, as shown in Chart 1 . This section discussed the intrinsic and extrinsic motivation that made the student enjoyed the program. The motivation background in completing OLEP was drawn from the interview.

Did you enjoy the program?

30 responses
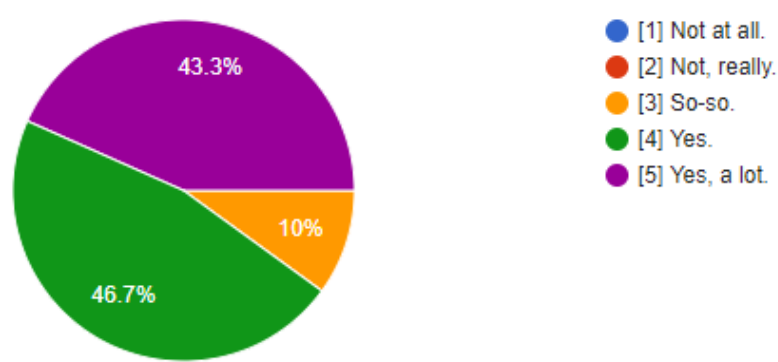

Chart 1. Student's enjoyment of OLEP

\section{Intrinsic Motivation}

Students with intrinsic goals aim to develop their understanding, success, and skills in a particular area (Radovan \& Makovec, 2015). The ten interviewees were happy when they informed that they were going to be involved in OLEP. They had high expectations to interact with Japanese, Taiwanese, or Chinese students as it was their first experience. For them, this program was an opportunity to develop their communication and English skills. It reflected from the interviewees as follows.

It is a good idea. Study English with other students in other countries makes me try and learn to be braver to talk English. [Respondent 10].

This program is good because we can learn English together, and check if our grammar is correct or not, and many more. [Respondent 5]

By writing an online letter to their buddy, students were intrinsically motivated to learn English and had English writing experience for real purposes. One fact that was revealed from the interview was the students' writing strategy. 
Some students utilize Google translate to write the letter. However, at least they were aware if they found ungrammatically correct sentences. By doing so, they learn.

\section{Extrinsic Motivation}

Based on the interview, almost all interviewees were motivated to complete OLEP because there was a $10 \%$ reward score to complete all stages of OLEP. This finding was in line with Gorshkov (2017) research, who also surveyed students' motivation in the letter exchange program, supporting that students' motivation for learning English was motivated by the need to learn or pass compulsory English courses. Moreover, the other two respondents were motivated to complete tasks in OLEP since they had many replies from International students, and their buddy always replied to their posts. For teenagers, getting replies and responses from others is rewarding that made the students actively engaged. These conditions reflected that most of the students were driven by external regulation, as in Ryan and Deci's (2000) extrinsic motivation types.

Other types of extrinsic motivation discovered in this research were Iidentification. After joining the program, some students realized the importance of learning English for communication purposes. As one of the interviewees said:

I think I feel clumsy when I study English with other students. But, I also think this is the best way to improve my English, although, sometimes I feel stuck [Respondent 7].

By joining this program, she was motivated to practice her English with overseas students. She also had a desire to continue her communication with her buddy outside the program through social media.

\section{Student's Perceptions}

The students' perception resulted from questionnaires and interviews. Thirty out of thirty-four students responded to fill in the questionnaire. The perception highlighted the topics in OLEP, the platform's use, and the interaction process with international students during the program.

\section{Topics in OLEP}

Regarding the topic that most appealing to the students, personal topic, or self-introduction $(60 \%)$ in stage one took a higher degree of interest, followed by the places and hometowns topic (56.7\%) in stage two. The next favorable topics were traditional and modern culture, which took $43.3 \%$ and $36.7 \%$. Those topics were integrated into stage two, "Nature and Culture." While agriculture and environment topics in stages 3 and 4 might be relevant to agricultural knowledge attainment, it might not be seen as an exciting topic to discuss.

Students liked introductory subjects, as they wanted to know more about their foreign buddies. The students wrote about their interests, place of birth, campus and lectures, and diverse general introductory topics in the introductory section. As one 
interviewee said, "I am curious about the learning system in Japan and their campus environment" [Respondent 7]. In contrast, another interviewee stated that they like it when their buddy told them about the local food in Japan, Taiwan, or China. As she stated, "what makes me want to keep reading (the posting) is when they talk about their local food, I like the way they explain the food" [Respondent 5].

Topics such as introductions, describing places, and all their local cultural attributes were interesting topics that could trigger more intensive interactions because the information contained in these topics might be new for Indonesian and international students. It also raised students' enthusiasm to posts and reply and tried to get acquainted with other foreign friends to gain further insight from their new pals. It could be seen from the progress bar that showed all students made posts and completed assignments on stage 1 and 2.

When asked about the most challenging stage to complete, the respondents' answers split into two, which showed stage $3(56.7 \%)$ and stage $4(43.3 \%)$, as in the chart 2 .

Which part was the most difficult for you in this program?

30 responses

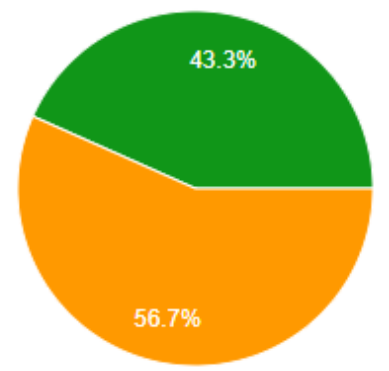

Stage 1: Self-Introduction and Our Places

Stage 2: Nature and Cultures

Stage 3: Discussion on Common

Themes

Stage 4: Local Environmental/

Agricultural Issues

\section{Chart 2. The most challenging stage and topic in OLEP}

Topics such as responding to videos and local Agricultural problems on stage 3 and 4 were considered unattractive and challenging because they had to see and understand the video first and wrote something related to it. Meanwhile, at stage four, some students found difficulties dealing with constructing paragraphs, using correct grammar, and deciding which topic they should write that interested their buddy. Some student's comments about stage three and four were summarized as follows:

[Stage 3]

because I have to watch the video with long duration and that's wasting my time

The video... I don't understand what they're talking about because I have to understand the video first before I write my opinion from that and for understanding the video is a little bit difficult for me

[Stage 4]

because need more efforts to understand (the topic) and need good grammar to full fill the tasks 
because I have to arrange the sentences into paragraphs that related to the topic

Because so many agricultural issues that makes me learn specifically about how that issues happened.

I'm confused what issue should I write that makes my buddy interested to my post.

This result confirmed previous research that conducted pre-survey to a similar exchange program (Guest \& Duyen, 2016). This evidence had shown that heavy topics related to the students' fields tend to get a lower rank of interest.

\section{The OLEP platform}

As explained previously, this program was a web-based and utilized Moodle for running its program. At the beginning of the program, students were given tutorials on how to post and reply to the platform. The perception of students about working with the Moodle platform was obtained from the questionnaire and interview.

The questionnaire results revealed that almost half of the students $(40 \%)$ said that it was easy to use Moodle, and $13.3 \%$ of the student stated that it was difficult, as shown in chart 3. It reflected that Moodle has a simple interface and feature that can be quickly learned and use for OLEP. The anomaly was that students could easily use the platform because they had training at the early stage, or even if they had not been trained, they could easily navigate the platform.

How easy it was for you to use this online system (moodle)?

30 responses

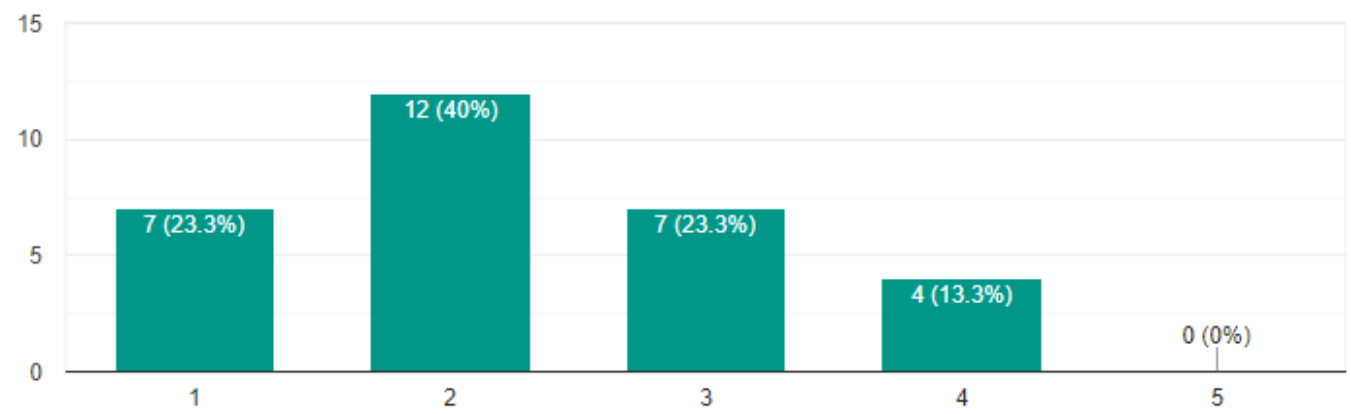

Chart 3. Using online system (Moodle)

On the other hand, the interview and the questionnaire revealed the students' critical perception regarding Moodle usages, such as the user interface and experience, the depth of the menu, and the notification issue.

First of all, the OLEP website's layout is sleek and minimalist with a white background, fewer pictures, and menu keys. The first page of the web displayed the teacher's name list from the participant country. Some of the respondents complained about the theme and log-in section as cited below: 
[Respondent 3]

The website and theme model have to be improved so that people will easily access the web.

[Respondent 10]

Maybe OLEP should improve in the design of the OLEP's "home" website.

[Respondent 12]

Change the theme of the website.

[Respondent 24]

The aspect of the program that should be improved in the future is the way to log in. Sometimes, it's difficult to log in because I forget my account. Maybe, log in using bar code is better.

The results showed that some students argue that they did not particularly like the appearance of too simple and static themes. It might be caused the target of this program was teenagers who might look for a more dynamic website or something more colorful. In contrast, the simple display had a goal to make the teenage students more focused. In a study by Joyce and Nielsen (2019), the presentation of content with much white space in small and meaningful sections helps teenage students grasp information quickly and stay focused on one particular area. Another reason behind the simple design was to reduce the loading time as teenagers are easily frustrated and impatient to wait for the slow loading time (Joyce and Nielsen, 2019).

The reason that students suggested to change the website design was the depth of the menu. To log in, they need to click on the teacher's name menu on the first page to get in the web's main courses. A student suggested the plug-in bar code for log-in to help students who often forgot password and username. While to post and reply, students must go through several sub-menus so that it seems impractical. The student required direct access for one push reply button below the students' post.

The next problem was dealing with the notification issue. There was no notification feature in OLEP, so that students needed to regularly check whether their buddy had replied to their post or not and checked whether their buddy had posted or not in each stage. This issue caused the students to make a late post or reply to their buddy. Some students stated that they forgot to post at the last stage because they were busy with other assignments, and there was no notification reminder for OLEP.

\section{Interaction}

This study's term interaction means the communication intensity between Indonesian students and International students in responding to their buddy's posts and others. As mentioned earlier, the requirement to complete each stage was for the students to make three replies to other country participants. According to the survey, $43.3 \%$ of the respondents received responses from other countries' 
participants, but not many. Meanwhile, $20 \%$ of the respondents did not receive any replies, and another $20 \%$ answered "so-so." The question flaw was the option "so so," which led to an ambiguous interpretation of whether the students got enough replies. It could be interpreted that the students gained a bit more responses than option 2, as shown in Chart 4. Only 6.7\%, which meant two students, did get many replies.

Did you receive enough replies from the other country's participants?

30 responses
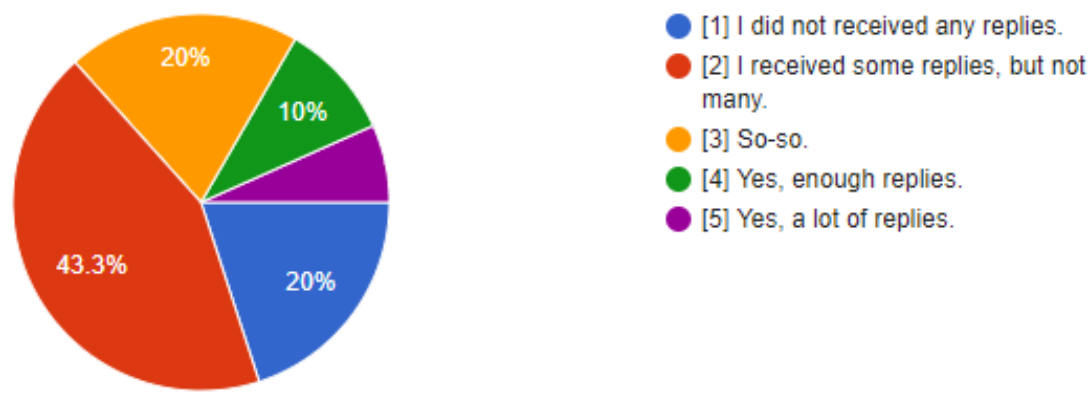

Chart 4. The number of replies from other country's participants.

The interview result discovered that some students complained that their buddies were neither post nor reply to their postings. The next problem is the gap time to reply to a post was relatively long. Some students just got a reply from their pals after two weeks. The Indonesian students were more enthusiastic than the International students as reflected from one of the respondents: maybe from the other participants from the other countries should be more attractive to us and give more intention to make the essay [respondent 30]. However, the answer to the low participation of International students had been investigated by Guest and Duyen (2016). The study depicted that online learning was not something new for international students, mainly Japanese students, who thought online learning was burdensome.

\section{CONCLUSIONS}

This research documents the motivation and perception of students regarding OLEP. In general, Indonesian students were very excited to participate in this program and seemed to have an opportunity to express themselves in English real use for friendship. The high interest of the program trigger students' motivation, intrinsically and extrinsically. Two types of extrinsic motivation, namely External regulation and Identification, were dominant motivation in completing the tasks in OLEP. However, the researchers advise setting up the learning outcome and describing how OLEP supports students' learning process at the beginning of the program. By doing so, it might lead the student to discover other intrinsic and extrinsic motivation.

A highlighted issue here is about the students' perceptions regarding the interaction with international students. The low degree of interaction and responses from others' participant countries might demotivate students and spark negative perceptions towards the program. Teachers from each participating country are recommended to encourage and monitor the level of interaction between students. 
If there is more interaction between participants, the more engagement and motivation will be.

The next issue was the platform interface and experience. It is suggested that the OLEP programmer and those who would like to conduct similar programs to provide notification and reminder features to reduce the delay in replying to the posts. Redesigning the web interface and simplify the menu access might increase teenage students' enjoyment in using the platform.

Finally, albeit the scope and number of this research may be small, we believe that our program's information and evaluation might be a valuable source for creating a similar program with a local context.

\section{REFERENCES}

Abu-Melhim, A.-R. (2013). Exploring the Historical Development of ESP and its Relation to English Language Teaching Today. European Journal of Social Sciences, 40, 615-627.

Agustina, T. (2014). English For Specific Purposes (ESP): An Approach of English Teaching for Non-English Department Students. Beta, 7(1), 37-63.

Buzdar, M. A., Mohsin, M. N., Akbar, R., \& Mohammad, N. (2017). Students' academic performance and its relationship with their intrinsic and extrinsic motivation. Journal of Educational Research, 20(1), 74.

Gorshkov, V. (2017). Motivating English Learning through International Friendship Letter Exchanges. The Bulletin of Kaichi International University, 16(January), 67-85. https://doi.org/10.24581/kaichi.16.0_67

Guest, M., \& Duyen, L. T. H. (2016). Student preferences, expectations and anxieties regarding an online exchange program: Reports from Japan and Vietnam. 3L: Language, Linguistics, Literature, 22(1), 67-79. https://doi.org/10.17576/3L-2016-2201-06

Indrasari, N. (2016). English for Specific Purposes: A Need Analysis at The Second Semester of Physics Education Students of IAIN Raden Intan Lampung in The Academic Year of 2015/2016. English Education: Jurnal Tadris Bahasa Inggris, 9(1), 161-172. Retrieved from http:ejournal.radenintan.ac.id/index.php/ENGEDU

Johns, A. M. (2012). The History of English for Specific Purposes Research. In. The Handbook of English for Specific Purposes.

Joyce, A., \& Nielsen, J. (2019). Teenager's UX: Designing for Teens. In Nielsen Norman Group (https://www.nngroup.com/articles/usability-of-webs). https://www.nngroup.com/articles/usability-of-websites-for-teenagers/

Lemos, M. S., \& Veríssimo, L. (2014). The Relationships between Intrinsic Motivation, Extrinsic Motivation, and Achievement, Along Elementary School. Procedia - Social and Behavioral Sciences, 112, 930-938. doi:https://doi.org/10.1016/j.sbspro.2014.01.1251.

Nurakhir, A., \& Palupi, F. N. (2018). Exploring ESP Needs of Undergraduate Nursing Students in a University in Indonesia. Advances in Social Sciences Research Journal, 5(7), 77-85. 
Pavel, E. (2020). Language Learner Motivation and Strategies in English for Medical Purposes. Philobiblon: Transylvanian Journal of Multidisciplinary Research in Humanities, 25(1), 125-138. doi:10.26424/philobib.2019.25.1.08

Radovan, M., \& Makovec, D. (2015). Relations between students' motivation, and perceptions of the learning environment. Center for Educational Policy Studies Journal, 5(2), 115-138.

Ryan, R. M., \& Deci, E. L. (2000). Intrinsic and Extrinsic Motivations: Classic Definitions and New Directions. Contemporary Educational Psychology, 25(1), 54-67. doi:https://doi.org/10.1006/ceps.1999.1020

Vatankhah, M., \& Tanbakooei, N. (2014). The Role of Social Support on Intrinsic and Extrinsic Motivation among Iranian EFL Learners. Procedia - Social and Behavioral Sciences, $\quad 98, \quad 1912-1918$. doi:https://doi.org/10.1016/j.sbspro.2014.03.622

Wallace, M. P., \& Leng Leong, E. I. (2020). Exploring Language Learning Motivation among Primary EFL Learners. Journal of Language Teaching \& Research, 11(2), 221-230. doi:10.17507/j1tr.1102.10 